\title{
Intraoperative radiation therapy induces immune response activity after pancreatic surgery
}

\author{
Yun Sun Lee ${ }^{1,2}$, Hyung Sun Kim¹, Yeona Cho ${ }^{3}$, Ik Jae Lee ${ }^{3}$, Hyo Jung Kim¹, Da Eun Lee ${ }^{1,2}$, \\ Hyeon Woong Kang ${ }^{1,2}$ and Joon Seong Park ${ }^{1 *}$
}

\begin{abstract}
Background: Pancreatic cancer has highly aggressive features, such as local recurrence that leads to significantly high morbidity and mortality and recurrence after successful tumour resection. Intraoperative radiation therapy $(\mathrm{IORT})$, which delivers targeted radiation to a tumour bed, is known to reduce local recurrence by directly killing tumour cells and modifying the tumour microenvironment.
\end{abstract}

Methods: Among 30 patients diagnosed with pancreatic cancer, 17 patients received IORT immediately after surgical resection. We investigated changes in the immune response induced by IORT by analysing the peritoneal fluid (PF) and blood of patients with and without IORT treatment after pancreatic cancer surgery. Further, we treated three pancreatic cell lines with PF to observe proliferation and activity changes.

Results: Levels of cytokines involved in the PISK/SMAD pathway were increased in the PF of IORT-treated patients. Moreover, IORT-treated PF inhibited the growth, migration, and invasiveness of pancreatic cancer cells. Changes in lymphocyte populations in the blood of IORT-treated patients indicated an increased immune response.

Conclusions: Based on the characterisation and quantification of immune cells in the blood and cytokine levels in the PF, we conclude that IORT induced an anti-tumour effect by activating the immune response, which may prevent pancreatic cancer recurrence.

Clinical trial registration: NCT03273374.

Keywords: Pancreatic cancer, Intraoperative radiation therapy, Immune response, Cytokine

\section{Background}

Pancreatic cancer is reportedly one of the most aggressive cancers and the fourth leading cause of cancerrelated deaths [1]. Despite improvements in treatment, the 5 -year survival of patients remains $<5 \%$. Moreover, although curative resection is the only choice for pancreatic cancer, it has been insufficient in improving long-

\footnotetext{
* Correspondence: jspark330@yuhs.ac

${ }^{1}$ Department of Surgery, Gangnam Severance Hospital, Yonsei University College of Medicine, 20, Eonju-ro 63 gil, Gangnam-gu, Seoul 06229, South Korea

Full list of author information is available at the end of the article
}

term survival [2]. Alternatively, radiation therapy could provide a treatment option to increase the survival rate of patients with pancreatic cancer by inducing the immune activity of cytokines.

The conventional external beam radiation therapy (EBRT) of pancreatic cancer is extremely challenging. Its effectiveness is limited because adequate radiation cannot be provided owing to the low tolerance of adjacent organs $[3,4]$. Recent advanced radiotherapy techniques, such as intensity-modulated radiotherapy (IMRT), image-guided radiotherapy (IGRT), magnetic resonance (MR)-guided RT, and particle therapy have improved

(c) The Author(s). 2021 Open Access This article is licensed under a Creative Commons Attribution 4.0 International License, which permits use, sharing, adaptation, distribution and reproduction in any medium or format, as long as you give appropriate credit to the original author(s) and the source, provide a link to the Creative Commons licence, and indicate if changes were made. The images or other third party material in this article are included in the article's Creative Commons licence, unless indicated otherwise in a credit line to the material. If material is not included in the article's Creative Commons licence and your intended use is not permitted by statutory regulation or exceeds the permitted use, you will need to obtain permission directly from the copyright holder. To view a copy of this licence, visit http://creativecommons.org/licenses/by/4.0/ The Creative Commons Public Domain Dedication waiver (http://creativecommons.org/publicdomain/zero/1.0/) applies to the data made available in this article, unless otherwise stated in a credit line to the data. 
outcomes in pancreatic cancer patients [5-7]. However, these treatments are limited to patients with unresectable or borderline resectable pancreatic cancer, and their clinical use as adjuvant to conventional treatments has not yet been established. Intraoperative radiation therapy (IORT) using a portable instrument delivers a single fraction of high-dose radiation during surgery $[8,9]$ that effectively focuses intense radiation to a desired site and simultaneously reduces toxicity to normal tissues $[4,10]$.

A high dose of radiation triggers immunogenic cell death and stimulates anti-cancer immune response [11, 12]. Irradiation activates IFN-dependent immunity via the formation of DAMP molecules and upregulates the expression of pro-inflammatory cytokine genes by regulating NF-kB [13]. These cytokine cascades are radiation dose-dependent and have shared characteristics. A number of studies have described the effects of various complex components in the inflammatory microenvironment that increase the therapeutic effect by controlling the dynamic anti-cancer immune response [14, 15]. Therefore, the anti-tumour immune response could be an important mechanism responsible for modulating the immunosuppressive microenvironment.

The only prospective randomised control trial to investigate the effectiveness of IORT to date was performed in Japan, although an increased survival was not confirmed [16]. However, other studies have shown that IORT significantly improves local control and overall survival in patients with pancreatic cancer by reducing post-operative complications and mortality [17, 18]. High-dose irradiation directly induces DNA damage in irradiated cells and changes the tumour microenvironment. According to Kulcenty et al., IORT not only alters the composition of anti-tumour-related cytokines in the surgical wound fluid, but also affects the tumorigenic properties of breast cancer [19]. Thus, research studies are currently underway to decipher the effects of IORT on the tumour microenvironment, but little is known about pancreatic cancer.

The aim of this study was to investigate changes in the tumour microenvironment after IORT and its effects on pancreatic cancer. We also examined changes in pancreatic cancer cell proliferation and invasiveness using peritoneal fluid (PF) samples from IORT-treated patients with pancreatic cancer. This study improves our understanding of how IORT-induced changes in the tumour microenvironment alter the immune response and induce anti-cancer immune activity in patients with pancreatic cancer.

\section{Methods}

\section{Patient selection}

This single-institution prospective phase II study was approved by the institutional review board (3-2015-0102) and written informed consent was obtained from each patient. Thirty patients diagnosed with pancreatic cancer at the Gangnam Severance Hospital from 2018 to 2019 underwent pancreatic resection (Supplementary Table S1, Supplementary Table S2). The eligibility criteria were as follows: 1) age 20 years or older; 2) histologically or clinically confirmed pancreatic carcinoma; 3) Eastern Cooperative Oncology Group (ECOG) performance status scores of $0-2$; 4) resectable disease defined as follows: absence of distant metastases; absence of direct involvement of the inferior vena cava or aorta; and clear fat planes around the celiac axis, hepatic artery, and superior mesenteric artery; 5) stage I-III disease as per the 7th edition of the American Joint Committee on Cancer (AJCC); 6) good bone marrow function (haemoglobin level $>10 \mathrm{~g} / \mathrm{dL}$, absolute neutrophil count $>1500 / \mathrm{mm}^{3}$, and platelet count $>100,000 / \mathrm{mm}^{3}$ ); and 7) adequate renal function (serum creatinine level $<1.4 \mathrm{mg} / \mathrm{dL}$ and blood urea nitrogen level $<20 \mathrm{mg} / \mathrm{dL}$ ). Patients who 1) had previously received RT to the abdominal area; 2) had a tumour bed that could not be adequately covered by the IORT field as defined by the radiation oncologist; 3) had received neoadjuvant chemotherapy; 4) had synchronous distant metastasis; 5) were pregnant or nursing; or 6) had any condition rendering them unsuitable for IORT (at the discretion of the physicians) were excluded from this study.

\section{Treatment scheme}

A total of 17 patients were treated with IORT (irradiated with a single dose of $10 \mathrm{~Gy}$ at a depth of $5 \mathrm{~mm}$ into the tumour bed) immediately after surgical resection, as previously described [20]. Patients were subjected to curative resection, either pylorus-preserving pancreatoduodenectomy (PPPD), distal pancreatectomy, or total pancreatectomy. A mobile $50-\mathrm{kV}$ X-ray source (Intrabeam, Carl Zeiss, Germany) was used for IORT. The target volume included the tumour bed, the celiac and superior mesenteric arteries, the mesenteric root, and the portal vein; any areas deemed at risk by the surgeon and radiation oncologist were also included. A spherical applicator with a diameter of $3.5 \mathrm{~cm}$ was used. An additional shielding device was attached to the spherical applicator, leaving only the bottom surface unshielded from which the X-ray beam was delivered to the tumour bed. The target volume was irradiated with a single dose of $10 \mathrm{~Gy}$, prescribed at a $5-\mathrm{mm}$ depth into the tumour bed.

\section{Peritoneal fluid collection}

Patients were divided into the group that received IORT (IORT PF, $n=17$ ) and the group that did not receive IORT (no IORT, $n=13$ ). PF was collected from the usual surgical drain $24 \mathrm{~h}$ after the surgery. Sterile filtered 
PF samples were centrifuged at $2100 \mathrm{rpm}$ for $15 \mathrm{~min}$ and then stored at $-80^{\circ} \mathrm{C}$.

\section{Blood sample collection and isolation of peripheral blood mononuclear cells}

Blood was collected three times from patients (post-operation day (POD) 1, 7, and 14) using vacutainer EDTA tubes (BD Biosciences, San Jose, CA, USA). Whole blood was diluted with Dulbecco's phosphate-buffered saline (DPBS), gently layered over an equal volume of FicollPaque solution (GE Healthcare, Logan, UT, USA), and centrifuged at $400 \mathrm{~g}$ for $30-40 \mathrm{~min}$. Peripheral blood mononuclear cells (PBMCs) were collected from the second layer, and any remaining platelets were gently washed off using DPBS. Cells were resuspended in freezing medium containing 10\% DMSO and 90\% foetal bovine serum (FBS; Biowest, Riverside, MO, USA) and stored at $-80^{\circ} \mathrm{C}$.

\section{Cell culture}

Mia PaCa-2, Panc1, and Aspc1 cells were obtained from American Type Culture Collection (Manassas, VA, USA). Cells were cultured in DMEM or RPMI medium (Biowest) supplemented with 10\% FBS (Biowest) and 1\% antibiotic-anti-mycotic reagent (Gibco, Waltham, MA, USA). Cells were incubated at $37^{\circ} \mathrm{C}$ in a humidified atmosphere under $5 \% \mathrm{CO}_{2}$.

\section{Cytokine array}

PF samples were assayed using the Human Cytokine Antibody Array kit (Abcam, Cambridge, UK) according to the manufacturer's instructions. Briefly, each sample was incubated for $24 \mathrm{~h}$ at $4{ }^{\circ} \mathrm{C}$ and then paired with biotinylated detector antibodies and horseradish peroxidase (HRP)-conjugated streptavidin. Each cytokine was analysed using chemiluminescence and levels were quantified using ImageJ software (National Institutes of Health, Bethesda, MD, USA).

\section{Flow cytometry}

Isolated PBMCs were stained with the following fluorochrome-conjugated monoclonal antibodies: antihuman APC-CD4 (eBioscience, San Diego, CA, USA), APC-cy7 CD8 (BD Biosciences, San Jose, CA, USA), PEcy5 CD25 (Biolegend, San Diego, CA, USA), PE-Cy7 Foxp3 (eBioscience), BV421 CD56 (BD Biosciences, San Jose, CA, USA), and APC-CD19 (Biolegend). Live cells were classified using propidium iodide (BD Biosciences, San Jose, CA, USA) staining. Lymphocytes were further subtyped by their staining properties as $\mathrm{T}$ cells (CD3+), Th cells $(\mathrm{CD} 3+\mathrm{CD} 4+)$, Tc cells $(\mathrm{CD} 3+\mathrm{CD} 8+)$, NK cells (CD3-CD56+), or Treg cells (CD4 + CD25 + FOXP3+). Treg cells were fixed and underwent permeabilisation using the Fix \& Perm Buffer (eBioscience), and stained cells were analysed using BD FACSCanto II Cell Analyzer (BD Biosciences, San Jose, CA, USA). FlowJo software (BD Biosciences, San Jose, CA, USA) was used for compensation and data analysis.

\section{Proliferation assays}

For the 2D proliferation assay, $1.5-3 \times 10^{3}$ cells per well were seeded into a 96-well cell culture plate. Cells were allowed to grow in serum-free medium supplemented with 5\% FBS or PF. After incubation for 4 days, reduced medium with 10\% WST-1 reagent (EZ-cytox, Dogen, Korea) was placed into the wells after aspiration of the growth medium. The absorbance of each well was measured at $450 \mathrm{~nm}$ using a VersaMax microplate reader (Molecular Devices, San Jose, CA, USA).

For the colony formation assay, 100-500 cells/well were seeded into six-well culture plates containing reduced serum medium supplemented with 5\% PF and antibiotics. The medium was replaced every 3 days until colonies formed. The rate of colony formation was different for each cell, usually taking 7-14 days. Cells were fixed in cold 100\% methanol for $30 \mathrm{~min}$, stained using $2.5 \%$ crystal violet, and then washed several times with phosphate-buffered saline (PBS). Colony formation was calculated manually and digitally using ImageJ software, where colony area versus total area was calculated based on staining intensity.

\section{Migration and invasion assays}

For the invasion assay, the $8 \mu \mathrm{m}$ pore size Transwell system (Corning, Midland, MI, USA) was coated with Matrigel (1:50, Corning) at $37^{\circ} \mathrm{C}$ for $1 \mathrm{~h}$. Then, $2 \times 10^{4}$ cells were seeded on the apical side of the Transwell chamber (24-well insert) in serum-free media. DMEM with $7 \%$ PF and 1\% antibiotic-anti-mycotic agent was added to the basal compartment. The cells were allowed to invade for at $37^{\circ} \mathrm{C} 24 \mathrm{~h}$. The cells that remained in the top chamber were gently scraped off using wet cotton swabs. The cells that invaded the basal side were fixed in methanol for $10 \mathrm{~min}$, stained with $0.2 \%$ crystal violet, and then washed multiple times with distilled water. The invasion assays were performed in triplicate.

For the scratch wound migration assay, $2 \times 10^{4}$ cells were seeded into a 96-well plate (Image lock, IncuCyte ${ }^{\mathrm{Tm}}$; Essen Bioscience, Ann Arbor, MI, USA), and wound scratches were made using a wound maker tool (Essen Bioscience) $18 \mathrm{~h}$ after plating. The media in each well was supplemented with $5 \%$ PF and $1 \%$ antibiotic-antimycotic agent, and FBS was used as positive control. Images of the migrated cells were captured automatically every $4 \mathrm{~h}$, and the relative wound density was analysed using IncuCyte ${ }^{\text {Ts }}$ Chemotaxis Cell Migration Software (Essen Bioscience). 


\section{Western blotting}

After the indicated treatment, cells were harvested and washed with ice-cold PBS and lysed using RIPA lysis buffer. Proteins $(30 \mu \mathrm{g}$ sample) were separated using SDS-PAGE and transferred onto nitrocellulose membranes, blocked in 5\% skim milk, and incubated with the following primary antibodies (1:1000): Anti-phosphosmad2, phospho-smad3, smad2, and smad3 (Cell Signaling Technology, Danvers, MA, USA), anti-Snail+slug (Abcam), anti-vimentin (Cell Signaling Technology), Ncadherin (BD Biosciences, San Jose, CA, USA), Ecadherin (BD Biosciences, San Jose, CA, USA), and $\gamma$ tubulin (Sigma-Aldrich, St. Louis, MO, USA). The membranes were then washed thrice with Tris-buffered saline and Tween 20 (TBST), followed by incubation with HRP-conjugated secondary antibody (1:7000, Cell Signaling Technology) in TBST with 3\% skim milk. Bound antibody was probed using ECL solution.(Bio-Rad, USA) Chemiluminescent signals were captured using X-ray films. All experiments were performed in triplicate.

\section{RNA isolation and qPCR}

After the indicated treatment, cells were collected, and their RNA was isolated using TRIZOL Reagent ${ }^{\circ}$ (SigmaAldrich) according to the manufacturer's instructions. Then, $0.2 \mu \mathrm{g}$ total isolate RNA was analysed via reverse transcriptase PCR using the One-Step RT-PCR Kit ( $i N$ $t R O N$ Biotechnology, Seongnam-Si, Korea). First-strand cDNA synthesis was performed with $1 \mu \mathrm{g}$ RNA as a template using the RT-qPCR cDNA Synthesis Kit (iNtRON Biotechnology), according to the manufacturer's instructions. RT-qPCR was performed using the SYBR qPCR reaction mix (Applied Biosystems, Foster City, CA, USA). The primer sequences used in this study are listed in Table 1. Relative mRNA expression level was calculated using the $2^{-\triangle \Delta C T}$ method, using GAPDH as the reference gene.

Table $1 \mathrm{gPCR}$ primer sequence

\begin{tabular}{lll}
\hline Gene & & $\mathbf{5}^{\prime}$-3' sequences \\
\hline Vimentin & Forward & CACGAAGAGGAATCCGGAGC \\
SNAIL & Reverse & CAGGGCGTCATTGTTCCG \\
& Forward & CAAGGAATACCTCAGCCTG \\
E-cadherin & Reverse & GGCTTCTCGCCAGTGTG \\
& Forward & TGCCCAGAAAATGAAAAAGG \\
N-cadherin & Reverse & GTGTATGTGGCAATGCGTC \\
& Forward & GGCATACACCATGCCATCTT \\
GAPDH & Reverse & GTGCATGAAGGACAGCCTCT \\
& Forward & GTCTCCTCTGACTTCAACAGCG \\
& Reverse & ACCACCCTGTTGCTGTAGCCAA \\
\hline
\end{tabular}

\section{Statistical methods}

Statistical analysis was performed using GraphPad Prism version 8.01 software (GraphPad Software, La Jolla, CA, USA). Unpaired $t$-test was performed for statistical analysis of cytokine array, cell proliferation, western blotting, and qPCR data. Wound healing assay and PBMC phenotyping data were analysed by two-way ANOVA. Differences were considered statistically significant at * $p<0.05$, *** $p \leq 0.01$.

\section{Results}

Peritoneal fluid from IORT-treated patients displayed cytokine composition changes

We investigated cytokine changes induced by IORT in the PF of 30 patients with pancreatic cancer (Fig. 1A). Our results revealed that the relative signal intensity of 19 cytokines were higher in the IORT PF group than in the no IORT group, whereas levels of 17 cytokines were decreased (Fig. 1B, Supplementary Table S3). Among them, the levels of IFN- $\gamma(p=0.0357)$ IL-15 $(p=0.0172)$, platelet-derived growth factor (PDGF)-BB $(p=0.0042)$, and TGF- $\beta(p=0.0174)$ differed significantly with respect to the presence or absence of IORT (Fig. 1C). We further investigated whether these cytokine profile differences were related to the activation of intracellular pathways in pancreatic cancer cells (Fig. 1D). Pancreatic cancer cells incubated with IORT-treated PF for $4 \mathrm{~h}$ displayed activated cytokine-related signalling pathways (PI3K-Akt, Smad2/3) compared with cells incubated with no IORT-treated PF (Fig. 1E). Hence, IORT altered the cytokines secreted into the peritoneal cavity after surgery.

IORT-treated PF suppressed pancreatic cancer cell growth Next, we performed WST-1-based proliferation assays on Mia PaCa-2, Panc1, and Aspc1 cells to confirm the influence of IORT-treated PF on pancreatic cancer cell proliferation (Fig. 2A). The proliferation of pancreatic cancer cells stimulated by no IORT-treated PF was comparable to that of cells cultured in complete media (with FBS). However, pancreatic cancer cells in the IORT PF group demonstrated significantly reduced proliferation compared with those in the no IORT PF group. This difference was most pronounced in the Panc1 cells. Additionally, a similar pattern of IORT influence was displayed in the colony formation assay (Fig. 2B). PF exerted a stimulating effect on pancreatic cancer cell proliferation, which was inhibited in the IORT PF group.

\section{IORT-treated PF decreased invasiveness and wound healing activity of pancreatic cancer cells}

Next, we analysed the effect of IORT-treated PF on the invasive capability of pancreatic cancer cells through a 3D Matrigel-coated Transwell-based assay using five 


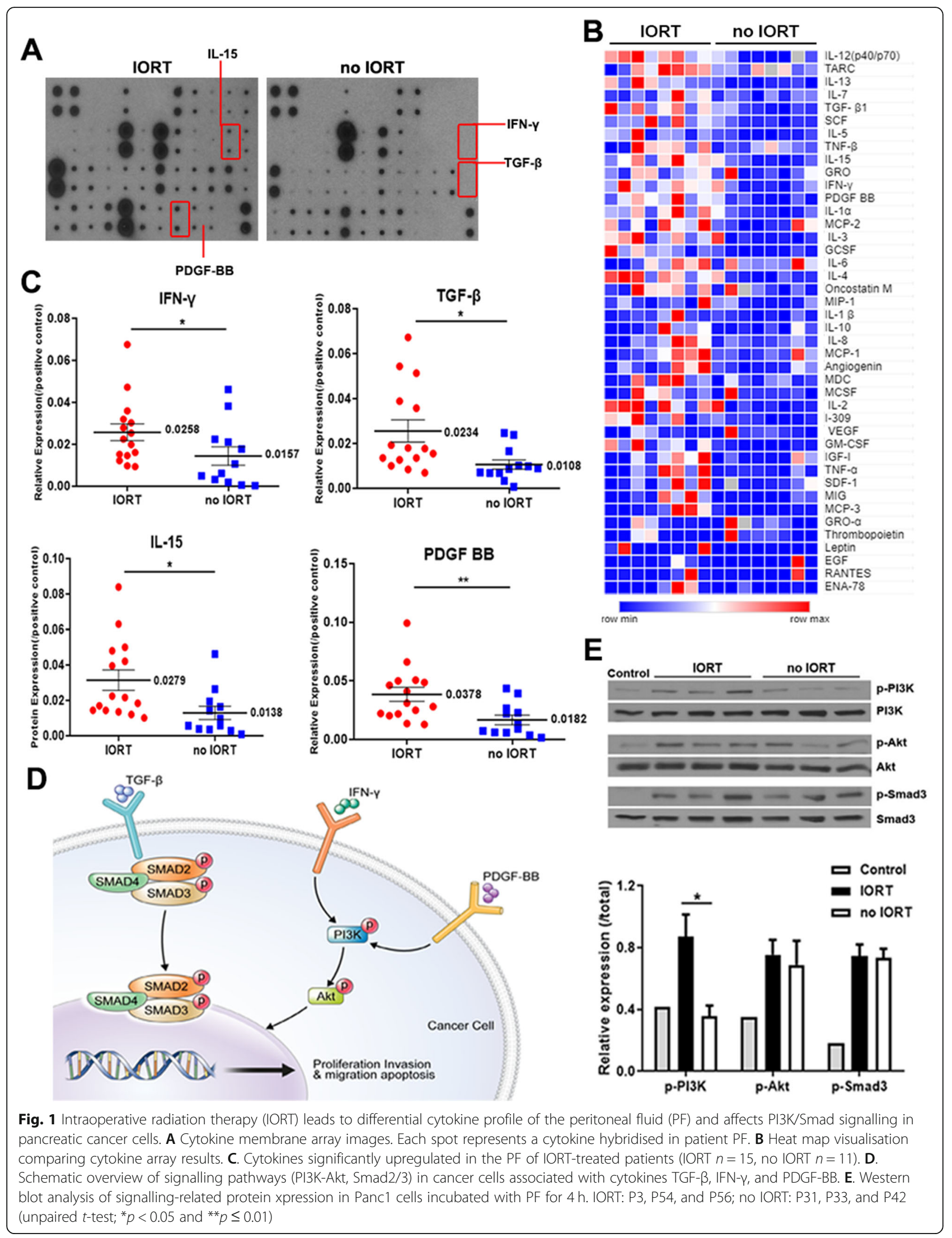




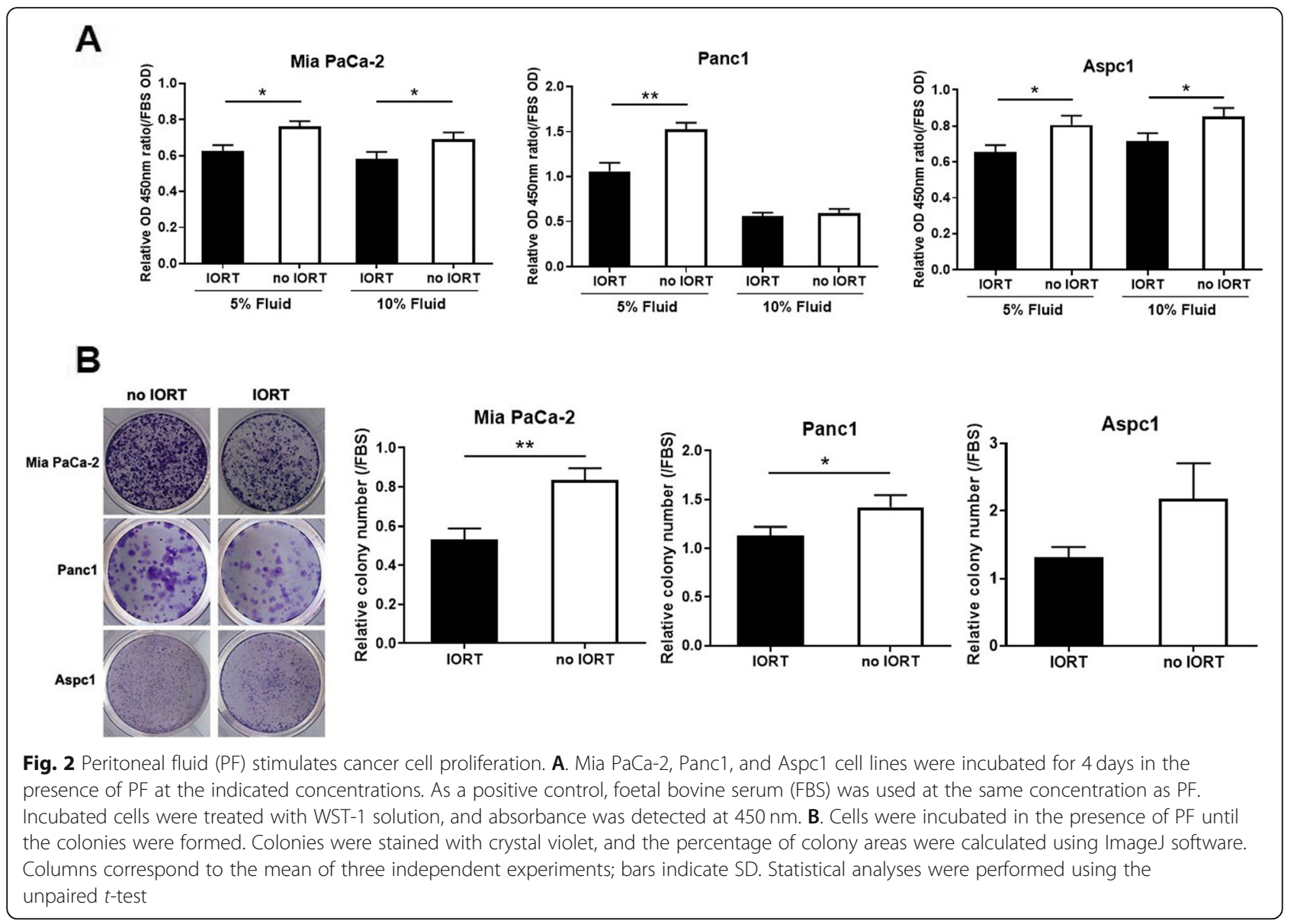

randomly selected PF samples from each group. Incubation with IORT-treated PF reduced the invasiveness of all three pancreatic cancer cell lines (Fig. 3A). Assessing the migratory ability of cells incubated with $\mathrm{PF}$ over time (Fig. 3B) revealed that cells in the IORT PF group had a slower wound closure rate than those in the no IORT group.

\section{IORT changed the expression of epithelial-mesenchymal transition (EMT) markers in pancreatic cancer cells}

We treated Mia PaCa-2, Panc1, and Aspc1 cells with the same 7\% PF used in the invasion assay. Comparing the average expression levels of EMT-related genes in PFtreated cells indicated that the expression of epithelial marker E-cadherin was increased, but that of mesenchymal markers vimentin, snail, and $\mathrm{N}$-cadherin was decreased in the IORT PF-treated cells (Fig. 4A). According to the western blot results, expression levels of the mesenchymal markers were decreased in the IORT PF group (Fig. 4B). These data implied that treatment with IORT-treated PF regulated the expression of EMT markers in pancreatic cancer cells, ultimately inhibiting cell invasiveness and migration activity.

\section{Changes in lymphocyte phenotypes indicated increased immune response after IORT}

Blood samples were collected from each patient group on POD 1, 7, and 14, after which flow cytometry was performed on the isolated PBMCs (Fig. 5A). The indicated immune cell population values on POD 7 and 14 were normalised to those on POD 1 (Fig. 5B). The total $\mathrm{T}$ cell population displayed a higher rate of increase during the 14-day post-operative period in the IORT PF group than in the no IORT group. Specifically, cytotoxic and helper $\mathrm{T}$ cell populations demonstrated significantly higher increasing rates in the IORT PF group than in the no IORT group. (Tc cell $p=0.0076$, Th cell $p=$ 0.0456) In the case of the NK cell population, a significantly higher increasing rate was observed during the first 7 days post-surgery in the IORT PF group than in the no IORT group. $(p=0.0216)$ Moreover, Treg cells maintained a reduced ratio throughout the 14-day postoperative period in the IORT PF group compared with that in the no IORT group. $(p=0.0242)$ These results indicated that IORT exerts a systemic effect on the microenvironment around the surgical site through the immune response. 


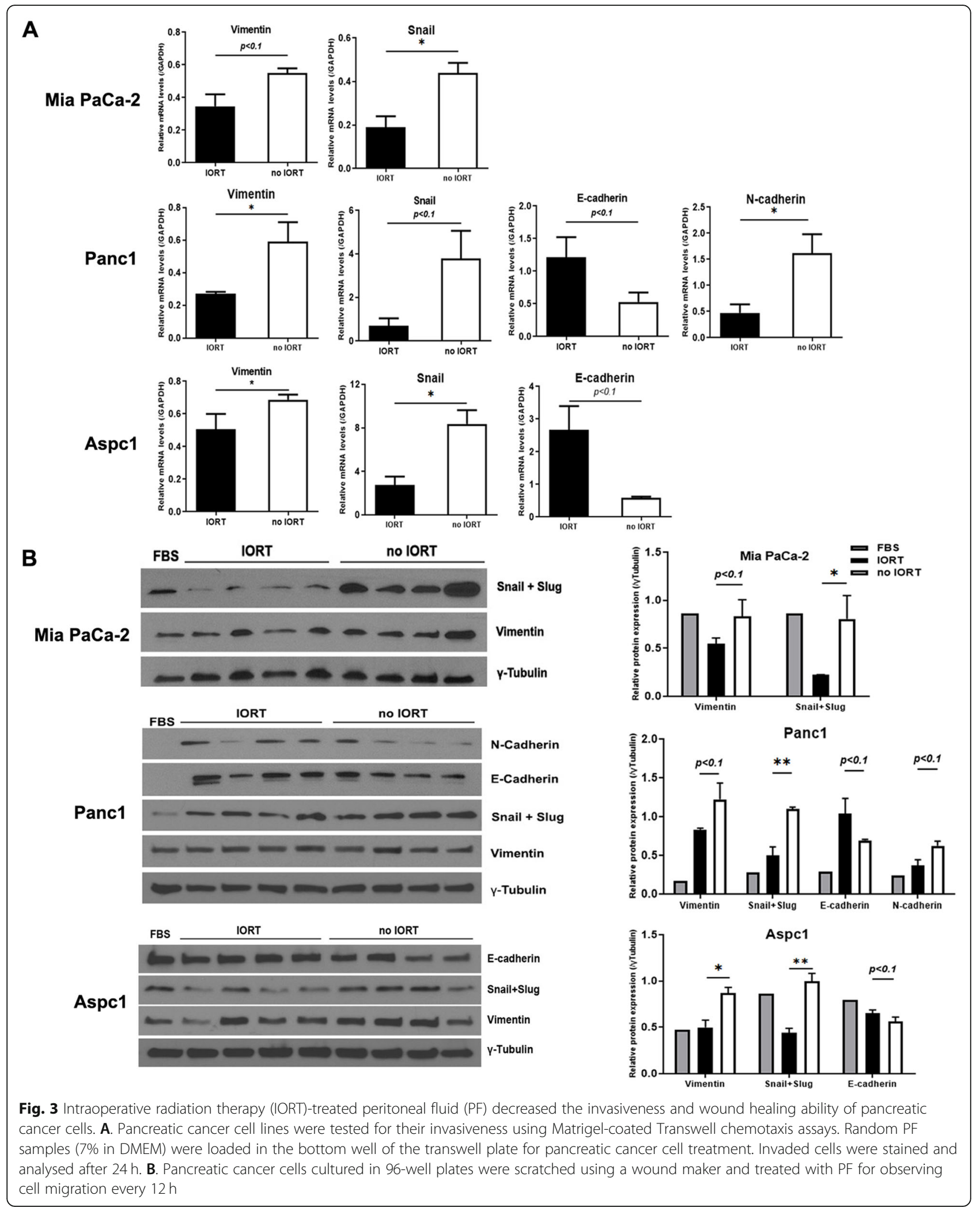




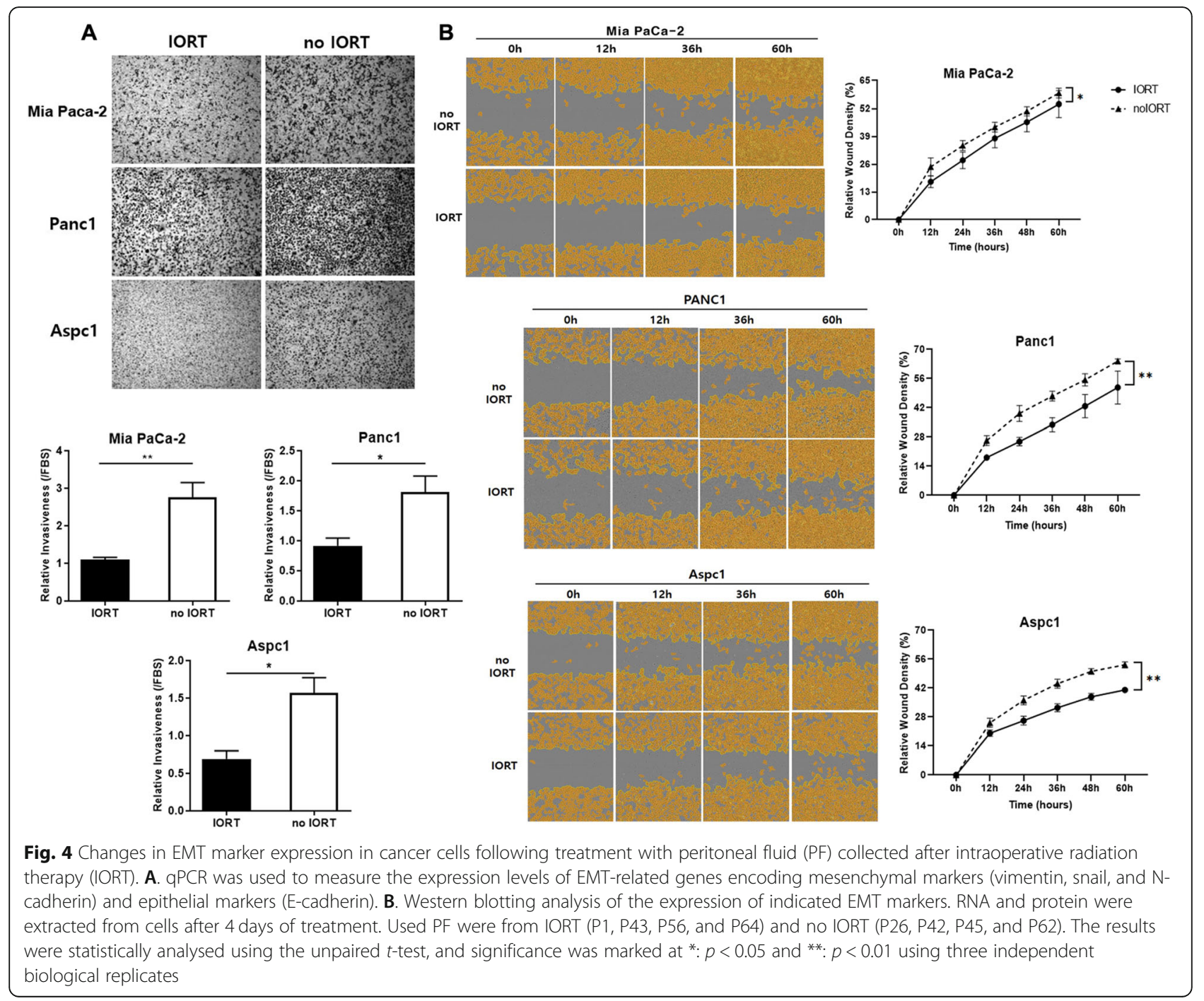

\section{Discussion}

Cytokines and growth factors secreted by tumour cells and surrounding cells are affected by radiation therapy and by invasive procedures, such as surgery [21, 22]. IFN, TGF- $\beta$, IL-1 $\beta$, IL-6, IL-7, and granulocytemacrophage colony-stimulating factor (GMCF) are known to regulate pro- and anti-immune responses [23]. In the current study, we identified cytokines secreted at elevated levels in the PF of IORT-treated patients with pancreatic cancer compared with those in the PF of patients who underwent surgical resection alone. Specifically, IFN- $\gamma$, TGF- $\beta$, IL-15, and PDGF-BB displayed significant differences between groups. TGF- $\beta$ is a cytokine with dual effects on cancer because it exerts inhibitory cancer activity in the early stages of carcinogenesis but promotes cancer growth in the later stages [24, 25]. In particular, increased TGF- $\beta$ secretion induces radioresistance and is known to be a major modulator of the anti-cancer immune response during radiation therapy
[26]. In our study, the TGF- $\beta$ level was significantly increased in the IORT PF group, likely owing to radiation response [27]. Among the relatively highly expressed cytokines, IFN- $\gamma$ is involved in mediating the anti-tumour effects of radiation therapy [28]. It is produced by related $\mathrm{CD} 8+\mathrm{T}$ and NK cells through immune stimulation or inflammatory reactions, and subsequently affects the activity of these cells after radiation exposure [29]. Concurring with the results of previous studies, our data confirmed that post-operative IORT maintained a relatively high proportion of CD8+ T and NK cells in the blood and increased the IFN- $\gamma$ level, which would lead to anti-cancer immune responses.

PDGF-BB, another relatively highly expressed cytokine, improves cell viability and induces cell proliferation and migration of several types of tumours. In accordance with our study results, PDGF-BB expression reportedly increases with TGF- $\beta$ expression throughout the radiation process [24]. PI3K-Akt signalling induced by 


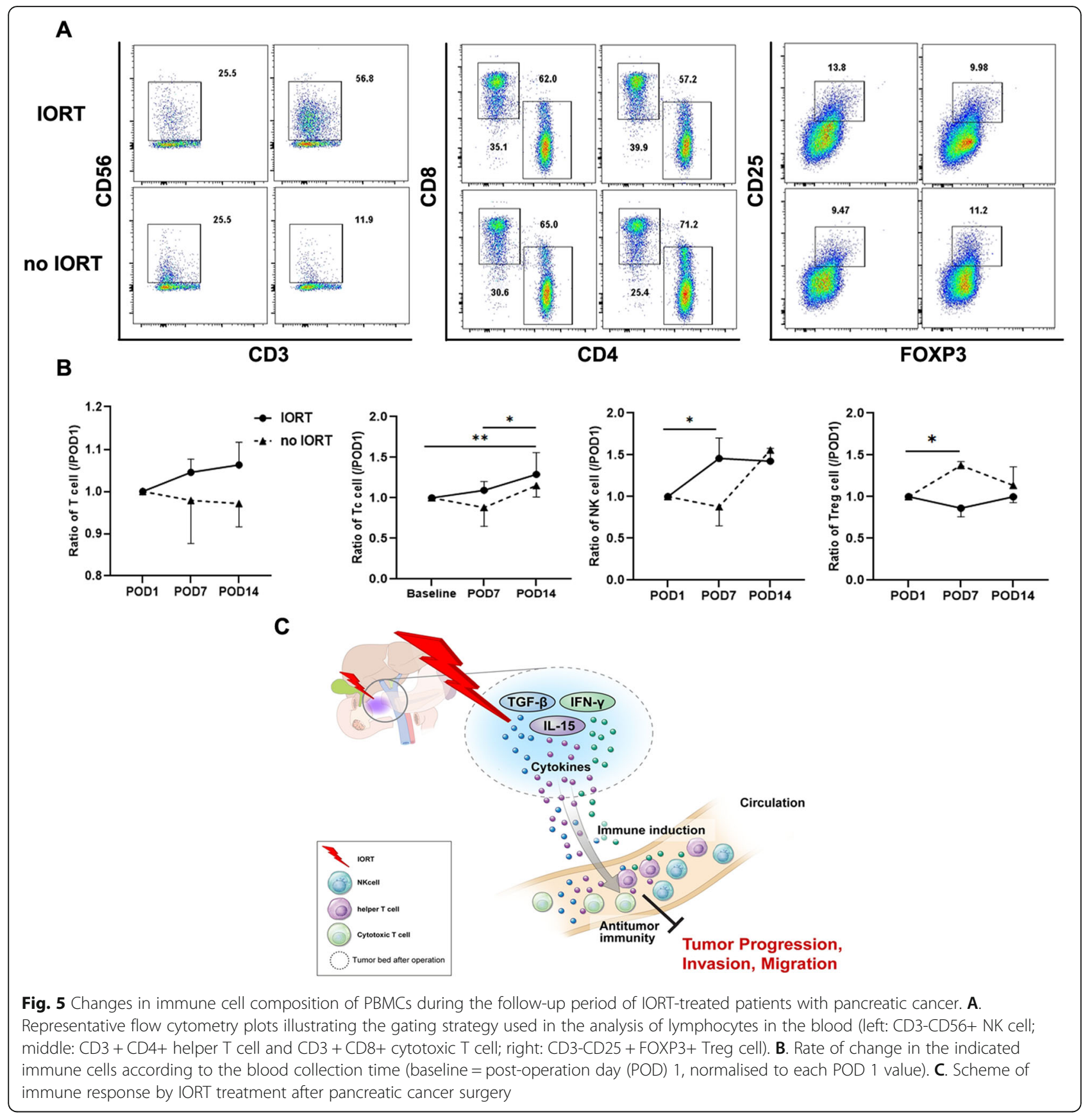

PDGF-BB is known to contribute to the migratory regulation of cancer progression [25]. Similar to the results of previous studies, PDGF-BB expression in the IORT PF group was elevated, and we confirmed that it affected PI3K-Akt signalling during PF treatment of pancreatic cancer cells. IL-15 is generally known to activate the innate immune system by inducing the differentiation and proliferation of NK cells [30]. In the present study, we confirmed its effect on PI3K-Akt signalling when pancreatic cancer cells were treated with PF, which concurred with similar results reported in a previous study
[31]. Nevertheless, to confirm the effect of IORT on immune cells, further comparative response studies are needed. According to a previous study investigating IORT in breast cancer, levels of PF, IL-4, and IL-5, which are known to be increased by radiation, were elevated, whereas those of IL-6, RANTES, and HGF, which are known to control tumour cell growth and motility, were decreased in the surgical wound fluid of breast cancer patients [32]. In another breast cancer study, levels of IL-7, IL-8, IL-13, macrophage migration inhibitory factor (MIF), and TNF- $\beta$ were increased, whereas those 
of CTACK, G-CSF, HGF, IL- $1 \beta$, and TNF- $\alpha$ were decreased after IORT exposure [19]. Although our data did not demonstrate significant differences in cytokine levels, except for IL- 8 and TNF- $\alpha$, a similar trend in the data suggests that immunological effects are induced by IORT in pancreatic cancer. The differences displayed by cytokines in our study compared with those in previous studies highlight that pancreatic cancer has higher heterogeneity than other types of cancer, which may lead to different tendencies that could be reflected in the pancreatic cancer tumour [33].

The cytokines and chemokines present in PF affect the EMT process of cancer cells, and ultimately, invasion and metastasis. TGF- $\beta 1$ reportedly induces the Smad4dependent EMT transition in Panc1 cells, increasing the $\mathrm{E}$-cadherin level while decreasing the $\mathrm{N}$-cadherin and vimentin levels [34]. CXCR4 also activates the Wnt and Hedgehog signalling pathways to express the EMT phenotype and promotes CXCL12-mediated pancreatic cancer cell invasion and metastasis [35]. Belletti et al. first reported the stimulating role of post-operative fluid on the proliferation and migration of breast cancer cells [32]. In particular, Kulcenty et al. observed expression of the EMT phenotype and induction of cell migration when breast cancer cells were treated with postoperative fluid, which was abrogated by IORT treatment [36]. In the present study, proliferation, invasion, and motility of all three pancreatic cell lines were stimulated by PF, the effects of which were suppressed in cells stimulated with IORT-treated PF. Epithelial and mesenchymal markers in pancreatic cancer cells were used to confirm inhibition of the EMT process, revealing the same pattern as the functional assay. These results are consistent with the above-mentioned studies, indicating that IORT-induced changes in the tumour microenvironment are responsible for suppression of the proliferation, invasiveness, and migratory ability of pancreatic cancer cells.

Analysing blood samples after surgery, we confirmed that the ratio of anti-tumour immune cells on POD 1 was decreased in most patients compared with that before surgery but was gradually recovered to preoperative levels over time (data not shown). Hence, we compared the proportion of immune cells that changed over time based on the levels measured on POD 1. Cytotoxic $\mathrm{T}$ cell and NK cell populations demonstrated a tendency towards higher increasing rates after surgery among patients who received IORT. Conversely, the abundance of Treg cells, which are immune suppressive cells, remained low in patients who received IORT. Irradiation of the cavity from which the tumour is removed causes apoptosis in the few remaining tumour cells and lymphocytes, and secretion of DAMP, tumour antigens, and cytokines, consequently establishing an environment that attracts immune cells, called the "bystander effect" [37, 38]. Our results support the formation of an inflammatory microenvironment induced by high-dose irradiation that can trigger an anti-tumour immune response in pancreatic cancer through the bystander effect. Pancreatic cancer is a representative "cold tumour"; the implementation of IORT may contribute to a positive feedback loop that continuously activates immune-related cells, thereby forming an immune environment that would improve local control of pancreatic cancer.

Drainage insertion after pancreatic cancer surgery is controversial; nevertheless, many surgeons perform draining because of complications caused by pancreatic fistulas [39]. Drainage fluid collected from the abdominal cavity of patients with pancreatic cancer has been used as a diagnostic indicator of pancreatic leaks or ascites, unlike wound fluid from breast cancer surgery [40, 41]. Various cancers, including pancreatic cancer, are known to protect malignant cells and accumulate fluid (malignant effusion) through the secretion of cytokines, growth factors, or peptides [42]. Several studies have investigated the tumour microenvironment through PF analysis for other cancer types, but little research has been conducted on PF in pancreatic cancer to date [43, 44]. The present study improves our understanding of the pancreatic cancer tumour microenvironment through component analysis and related signalling pathways in the $\mathrm{PF}$, with respect to IORT after pancreatic cancer surgery. However, further evaluation is needed to compare serum cytokine levels and more accurately correlate immune responses altered by IORT.

The local recurrence rate of pancreatic cancer is high even after radical surgery and adjuvant chemotherapy [2]. In our study, among patients who underwent surgery, local recurrence occurred in $31.3 \%(5 / 16)$ of patients who received IORT and 50\% (5/10) of those who did not receive IORT (Supplementary Table S4). In addition, when the 1-year disease-free survival rate was analysed based on the 2-year follow-up data, it was confirmed that the IORT group had a higher rate (Supplementary Fig. S1). Although they did not reach statistical significance, these findings support disease-free survival and local recurrence benefits via IORT of pancreatic cancer.

This study has several limitations that should be acknowledged when interpreting the results. First, this was a prospective study with nonrandomised patients because it was classified according to patient consent. Second, because the PF used in this study was derived from the entire abdominal cavity, it is possible that the other factors such as stress and inflammation from surgery, in addition to IORT, may have influenced the results. Third, only the indirect immune effects by IORT could 
be confirmed through the ratio analysis of PBMC cells using blood.

\section{Conclusion}

This is the first study to employ blood and PF to confirm the effect of IORT on pancreatic cancer cells and the anti-cancer immune response after surgical resection. We identified differentially expressed cytokines in PF and compared the effect of IORT administration on the proliferation and activity of pancreatic cancer cells stimulated by PF. We also confirmed the anti-cancer immune response induced by IORT through comparison of immune cell populations during the postoperative period. Through this study, we can conclude that various cytokines at the surgical site induce microenvironment changes after IORT, which inhibit the proliferation of remaining cancer cells and recurrence (Fig. 5C). Therefore, IORT induces an anti-cancer immune response in patients with pancreatic cancer, ultimately aiding local control and prevention of pancreatic cancer recurrence.

\section{Supplementary Information}

The online version contains supplementary material available at https://doi. org/10.1186/s12885-021-08807-3.

\section{Additional file 1 Supplementary Table S1. Summary of patients'} clinical characteristics.

Additional file $\mathbf{2}$ Supplementary Table S2. Clinical characteristic of 30 patients.

Additional file 3 Supplementary Table S3. Cytokine levels in PF altered by IORT.

Additional file $\mathbf{4}$ Supplementary Table S4. Recurrence pattern of patients with pancreatic cancer.

Additional file $\mathbf{5}$ Supplementary Fig. S1. 1-year disease free survival rate according to IORT

\section{Acknowledgments}

The authors thank Medical Illustration \& Design, part of the Medical Research Support Services of Yonsei University College of Medicine, for all artistic support related to this work.

\section{Authors' contributions}

Yun Sun Lee: Methodology, Formal Analysis, Investigation, Data Curation, Writing - Original Draft, Visualisation. Hyung Sun Kim: Resources, Data Curation. Yeona Cho and Ik Jae Lee: Resources. Hyo Jung Kim: Writing Review \& Editing. Da Eun Lee \& Hyeon Woong Kang: Validation, Data Curation. Joon Seong Park: Conceptualisation, Writing - Review \& Editing, Supervision, Project Administration. The author(s) read and approved the final manuscript.

\section{Funding}

This study was supported by the 2020 Research Grant of Gangnam Severance Hospital Research Committee.

\section{Availability of data and materials}

The datasets used and/or analysed during the current study are available from the corresponding author on reasonable request.

\section{Declarations}

Ethics approval and consent to participate

This single-institution prospective phase II study was approved by the institutional review board (protocol number: 3-2015-0102) in 2017 and has been registered at www.clinicaltrials.gov (NCT03273374).

\section{Consent for publication}

Informed consent was obtained from all individual participants included in the study.

\section{Competing interests}

The authors declare no conflict of interest.

\section{Author details}

'Department of Surgery, Gangnam Severance Hospital, Yonsei University College of Medicine, 20, Eonju-ro 63 gil, Gangnam-gu, Seoul 06229, South Korea. ${ }^{2}$ Brain Korea 21 FOUR Project for Medical Science, Yonsei University, Seoul, South Korea. ${ }^{3}$ Department of Radiation Oncology, Yonsei University College of Medicine, Seoul, South Korea.

Received: 8 June 2021 Accepted: 23 September 2021

Published online: 12 October 2021

\section{References}

1. Kane S, Engelhart A, Guadagno J, Jones A, Usoro I, Brutcher E. Pancreatic ductal adenocarcinoma: characteristics of tumor microenvironment and barriers to treatment. J Adv Pract Oncol. 2020;11(7):693-8. https://doi.org/10. 6004/jadpro.2020.11.7.4.

2. Siegel RL, Miller KD, Jemal A. Cancer statistics, 2019. CA Cancer J Clin. 2019; 69(1):7-34. https://doi.org/10.3322/caac.21551.

3. Paunesku T, Woloschak GE. Future directions of intraoperative radiation therapy: a brief review. Front Oncol. 2017;7:300. https://doi.org/10.3389/ fonc.2017.00300.

4. Krempien $R$, Roeder F. Intraoperative radiation therapy (IORT) in pancreatic cancer. Radiat Oncol. 2017;12(1):8. https://doi.org/10.1186/s13014-016-07530 .

5. Boldrini L, Cusumano D, Cellini F, Azario L, Mattiucci GC, Valentini V. Online adaptive magnetic resonance guided radiotherapy for pancreatic cancer: state of the art, pearls and pitfalls. Radiat Oncol. 2019;14(1):71. https://doi. org/10.1186/s13014-019-1275-3.

6. Heerkens HD, van Vulpen M, Erickson B, Reerink O, Intven MP, van den Berg CA, et al. MRI guided stereotactic radiotherapy for locally advanced pancreatic cancer. Br J Radiol. 2018;91(1091):20170563. https://doi.org/10.12 59/bjr.20170563.

7. Reese AS, Lu W, Regine WF. Utilization of intensity-modulated radiation therapy and image-guided radiation therapy in pancreatic cancer: is it beneficial? Semin Radiat Oncol. 2014;24(2):132-9. https://doi.org/10.1016/j. semradonc.2013.11.003.

8. Kinsella TJ, Sindelar WF. Intraoperative radiotherapy for pancreatic carcinoma. Experimental and clinical studies. Cancer. 1996;78(3 Suppl):598604. https://doi.org/10.1002/(SICI)1097-0142(19960801)78:3+<598::AIDCNCR4>3.0.CO;2-7.

9. Crane $\mathrm{CH}$, Beddar AS, Evans DB. The role of intraoperative radiotherapy in pancreatic cancer. Surg Oncol Clin N Am. 2003;12(4):965-77. https://doi. org/10.1016/S1055-3207(03)00090-5.

10. Pilar A, Gupta M, Ghosh Laskar S, Laskar S. Intraoperative radiotherapy: review of techniques and results. Ecancermedicalscience. 2017;11:750. https://doi.org/10.3332/ecancer.2017.750.

11. Demaria S, Formenti SC. Radiation as an immunological adjuvant: current evidence on dose and fractionation. Front Oncol. 2012;2:153. https://doi. org/10.3389/fonc.2012.00153.

12. Kroemer G, Galluzzi L, Zitvogel L. Immunological effects of chemotherapy in spontaneous breast cancers. Oncoimmunology. 2013;2(12):e27158. https:// doi.org/10.4161/onci.27158.

13. Hellweg CE. The nuclear factor kappaB pathway: a link to the immune system in the radiation response. Cancer Lett. 2015;368(2):275-89. https:// doi.org/10.1016/j.canlet.2015.02.019.

14. Shan $Y X$, Jin SZ, Liu XD, Liu Y, Liu SZ. Ionizing radiation stimulates secretion of pro-inflammatory cytokines: dose-response relationship, mechanisms and 
implications. Radiat Environ Biophys. 2007;46(1):21-9. https://doi.org/10.1 007/s00411-006-0076-x.

15. Di Maggio FM, Minafra L, Forte Gl, Cammarata FP, Lio D, Messa C, et al. Portrait of inflammatory response to ionizing radiation treatment. J Inflamm (Lond). 2015;12(1):14. https://doi.org/10.1186/s12950-015-0058-3.

16. Kinoshita T, Uesaka K, Shimizu Y, Sakamoto H, Kimura W, Sunada S, et al. Effects of adjuvant intra-operative radiation therapy after curative resection in pancreatic cancer patients : Results of a randomized study by 11 institutions in Japan. J Clin Oncol. 2009;27(15_suppl):4622.

17. Jin L, Shi N, Ruan S, Hou B, Zou Y, Zou X, et al. The role of intraoperative radiation therapy in resectable pancreatic cancer: a systematic review and meta-analysis. Radiat Oncol. 2020;15(1):76. https://doi.org/10.1186/s13014-02 0-01511-9.

18. Chen $Y$, Che $X$, Zhang J, Huang H, Zhao D, Tian $Y$, et al. Long-term results of intraoperative electron beam radiation therapy for nonmetastatic locally advanced pancreatic cancer: retrospective cohort study, 7-year experience with 247 patients at the National Cancer Center in China. Medicine (Baltimore). 2016;95(38):e4861. https://doi.org/10.1097/MD.0000000000004 861.

19. Kulcenty K, Piotrowski I, Wroblewska JP, Wasiewicz J, AWM S. The Composition of Surgical Wound Fluids from Breast Cancer Patients is Affected by Intraoperative Radiotherapy Treatment and Depends on the Molecular Subtype of Breast Cancer. Cancers (Basel). 2019;12(1):11. https:// doi.org/10.3390/cancers12010011.

20. Kim JW, Cho Y, Kim HS, Choi WH, Park JS, Lee IJ. A phase II study of intraoperative radiotherapy using a low-energy $x$-ray source for resectable pancreatic cancer: a study protocol. BMC Surg. 2019;19(1):31. https://doi. org/10.1186/s12893-019-0492-X.

21. Alfieri S, Morganti AG, Di Giorgio A, Valentini V, Bossola M, Trodella L, et al. Improved survival and local control after intraoperative radiation therapy and postoperative radiotherapy: a multivariate analysis of 46 patients undergoing surgery for pancreatic head cancer. Arch Surg. 2001;136(3):3437. https://doi.org/10.1001/archsurg.136.3.343.

22. Valeta-Magara A, Hatami R, Axelrod D, Roses DF, Guth A, Formenti SC, et al. Pro-oncogenic cytokines and growth factors are differentially expressed in the post-surgical wound fluid from malignant compared to benign breast lesions. Springerplus. 2015;4(1):483. https://doi.org/10.1186/s40064-015-12608.

23. Walle T, Martinez Monge R, Cerwenka A, Ajona D, Melero I, Lecanda F. Radiation effects on antitumor immune responses: current perspectives and challenges. Ther Adv Med Oncol. 2018;10:1758834017742575. https://doi. org/10.1177/1758834017742575.

24. Heldin $\mathrm{CH}$. Simultaneous induction of stimulatory and inhibitory signals by PDGF. FEBS Lett. 1997;410(1):17-21. https://doi.org/10.1016/S0014-5793 (97)00318-9

25. Fan H, Ma L, Fan B, Wu J, Yang Z, Wang L. Role of PDGFR-beta/PI3KNAKT signaling pathway in PDGF-BB induced myocardial fibrosis in rats. Am J Transl Res. 2014;6(6):714-23.

26. Rodriguez-Ruiz ME, Rodriguez I, Mayorga L, Labiano T, Barbes B, Etxeberria I, et al. TGFbeta blockade enhances radiotherapy Abscopal efficacy effects in combination with anti-PD1 and anti-CD137 Immunostimulatory monoclonal antibodies. Mol Cancer Ther. 2019;18(3):621-31. https://doi.org/10.1158/153 5-7163.MCT-18-0558

27. Dancea HC, Shareef MM, Ahmed MM. Role of radiation-induced TGF-beta signaling in Cancer therapy. Mol Cell Pharmacol. 2009;1(1):44-56. https://doi. org/10.4255/mcpharmacol.09.06.

28. Gerber SA, Sedlacek AL, Cron KR, Murphy SP, Frelinger JG, Lord EM. IFNgamma mediates the antitumor effects of radiation therapy in a murine colon tumor. Am J Pathol. 2013;182(6):2345-54. https://doi.org/10.1016/j.a jpath.2013.02.041.

29. Ivashkiv LB. IFNgamma: signalling, epigenetics and roles in immunity, metabolism, disease and cancer immunotherapy. Nat Rev Immunol. 2018; 18(9):545-58. https://doi.org/10.1038/s41577-018-0029-z.

30. Rautela J, Huntington ND. IL-15 signaling in NK cell cancer immunotherapy. Curr Opin Immunol. 2017;44:1-6. https://doi.org/10.1016/j.coi.2016.10.004.

31. Ali AK, Nandagopal N, Lee SH. IL-15-PI3K-AKT-mTOR: a critical pathway in the life journey of natural killer cells. Front Immunol. 2015;6:355. https://doi. org/10.3389/fimmu.2015.00355.

32. Belletti B, Vaidya JS, D'Andrea S, Entschladen F, Roncadin M, Lovat F, et al. Targeted intraoperative radiotherapy impairs the stimulation of breast cancer cell proliferation and invasion caused by surgical wounding. Clin
Cancer Res. 2008;14(5):1325-32. https://doi.org/10.1158/1078-0432.CCR07-4453.

33. Cros J, Raffenne J, Couvelard A, Pote N. Tumor heterogeneity in pancreatic adenocarcinoma. Pathobiology. 2018;85(1-2):64-71. https://doi.org/10.1159/ 000477773 .

34. Zhao M, Mishra L, Deng CX. The role of TGF-beta/SMAD4 signaling in cancer. Int J Biol Sci. 2018;14(2):111-23. https://doi.org/10.7150/ijbs.23230.

35. Singh AP, Arora S, Bhardwaj A, Srivastava SK, Kadakia MP, Wang B, et al. CXCL12/CXCR4 protein signaling axis induces sonic hedgehog expression in pancreatic cancer cells via extracellular regulated kinase- and Akt kinasemediated activation of nuclear factor kappaB: implications for bidirectional tumor-stromal interactions. J Biol Chem. 2012;287(46):39115-24. https://doi. org/10.1074/jbc.M112.409581.

36. Kulcenty K, Piotrowski I, Zaleska K, Wichtowski M, Wroblewska J, Murawa D, et al. Wound fluids collected postoperatively from patients with breast cancer induce epithelial to mesenchymal transition but intraoperative radiotherapy impairs this effect by activating the radiation-induced bystander effect. Sci Rep. 2019;9(1):7891. https://doi.org/10.1038/s41598-01 9-44412-y.

37. Brown JM, Koong AC. High-dose single-fraction radiotherapy: exploiting a new biology? Int J Radiat Oncol Biol Phys. 2008;71(2):324-5. https://doi. org/10.1016/j.jijobp.2008.02.003.

38. Herskind C, Wenz F, Giordano FA. Immunotherapy combined with large fractions of radiotherapy: stereotactic radiosurgery for brain metastasesimplications for intraoperative radiotherapy after resection. Front Oncol. 2017;7:147. https://doi.org/10.3389/fonc.2017.00147.

39. Cecka F, Lovecek M, Jon B, Skalicky P, Subrt Z, Neoral C, et al. Intraabdominal drainage following pancreatic resection: a systematic review. World J Gastroenterol. 2015;21(40):11458-68. https://doi.org/10.3748/wjg. v21.i40.11458.

40. Davidson TB, Yaghoobi M, Davidson BR, Gurusamy KS. Amylase in drain fluid for the diagnosis of pancreatic leak in post-pancreatic resection. Cochrane Database Syst Rev. 2017;4(4):CD012009. https://doi.org/10.1002/14 651858.CD012009.pub2.

41. Hicks AM, Chou J, Capanu M, Lowery MA, Yu KH, O'Reilly EM. Pancreas adenocarcinoma: ascites, clinical manifestations, and management implications. Clin Colorectal Cancer. 2016;15(4):360-8. https://doi.org/10.101 6/j.clcc.2016.04.014.

42. Kassis J, Klominek J, Kohn EC. Tumor microenvironment: what can effusions teach us? Diagn Cytopathol. 2005;33(5):316-9. https://doi.org/10.1002/dc.202 80.

43. Worzfeld T, Pogge von Strandmann E, Huber M, Adhikary T, Wagner U, Reinartz S, et al. The Unique Molecular and Cellular Microenvironment of Ovarian Cancer. Front Oncol. 2017;7:24. https://doi.org/10.3389/fonc.2017. 00024.

44. Wright EC, Connolly P, Vella M, Moug S. Peritoneal fluid biomarkers in the detection of colorectal anastomotic leaks: a systematic review. Int J Color Dis. 2017;32(7):935-45. https://doi.org/10.1007/s00384-017-2799-3.

\section{Publisher's Note}

Springer Nature remains neutral with regard to jurisdictional claims in published maps and institutional affiliations.

Ready to submit your research? Choose BMC and benefit from:

- fast, convenient online submission

- thorough peer review by experienced researchers in your field

- rapid publication on acceptance

- support for research data, including large and complex data types

- gold Open Access which fosters wider collaboration and increased citations

- maximum visibility for your research: over $100 \mathrm{M}$ website views per year

At BMC, research is always in progress.

Learn more biomedcentral.com/submissions 